\title{
VARIABILIDADE GENÉTICA PARA CARACTERÍSTICAS AGRONÔMICAS SUPERIORES EM CRUZAMENTOS BIPARENTAIS DE AVEIA PRETA (1)
}

\author{
GUSTAVO DA SILVEIRA $\left(\left(^{2}\right)\right.$; ENRIQUE MOLITERNO $\left({ }^{3}\right)$; GUILHERME RIBEIRO $\left({ }^{2}\right)$; \\ FERNANDO IRAJÁ FÉLIX DE CARVALHO $\left({ }^{2}\right)$; ANTONIO COSTA DE OLIVEIRA $\left({ }^{2}\right)$; \\ RAFAEL NORNBERG $\left({ }^{2}\right)$; DIEGO BARETTA $\left({ }^{2}\right)$; ITAMARA MEZZALIRA $\left({ }^{2}\right)$
}

\begin{abstract}
RESUMO
A aveia preta no Brasil tem apresentado um forte incremento em área cultivada, principalmente com o advento da semeadura direta, rotação de culturas e adoção de sistemas agropecuários. Mesmo com estas características existem poucos trabalhos de pesquisa voltados para esta cultura, especialmente quanto a caracteres de importância agronômica e a identificação de genótipos adaptados às necessidades do produtor agrícola. Diante disto, o objetivo do trabalho foi avaliar caracteres relacionados à produção de forragem e dormência de sementes em populações de aveia preta originadas de cruzamentos artificiais realizados entre linhagens derivadas da cultivar "Preta Comum" e cultivares comerciais da espécie. Dois experimentos foram desenvolvidos no inverno de 2008, no município de Capão do Leão (RS), o primeiro com o objetivo de testar caracteres forrageiros e o segundo, para medir caracteres das sementes, como rendimento e nível de dormência. Os resultados indicaram que a hibridação artificial intensificou a variabilidade genética melhorando a expressão dos caracteres forrageiros, de rendimento de sementes e nível de dormência nas sementes. O caráter estande de plantas evidenciou elevada relação com a produtividade de matéria seca em estádios de desenvolvimento precoce das plantas; em fases mais adiantadas o número de afilhos teve maior contribuição na produção de biomassa. De modo geral, nas hibridações artificiais houve respostas diferenciadas para rendimento de sementes e nível de dormência, variando com os genitores utilizados na obtenção das populações.
\end{abstract}

Palavras-chave: Avena strigosa Schreb., populações híbridas, produção de forragem, dormência nas sementes.

\section{ABSTRACT}

\section{GENETIC VARIABILITY FOR TOP AGRONOMIC CHARACTERISTICS IN BIPARENTAL CROSSES OF BLACK OATS}

The area sown to black oat in Brazil has experienced a dramatic growth as a consequence of the expansion of minimum tillage, crop rotations and crop-livestock systems. This growth was not accompanied by research work providing data on the relevant agronomic traits from this forage grass, which would eventually lead to the creation of new varieties meeting the growers' demands. This work evaluated traits related to forage production and seed dormancy in black oat populations originating from artificial breeding between pure lines derived from the "Preta Comum" variety and commercial varieties from this species. Two experiments were carried out during the winter of 2008, at the Capão do Leão, Rio Grande do Sul State, one to assess forage production traits and the second to measure seed traits such as yield and dormancy levels. The results showed that artificial breeding enhanced genetic variability through improvement on the expression of forage traits, seed yield and dormancy levels. In relation to the former, plant stand was highly associated to dry matter production during the early stages of seedling development and establishment, while tiller production remained the major component explaining biomass production later stages of forage production. Artificial breeding produced large differences on seed-related traits such as yield and dormancy level, suggesting the existence of adequate levels of variability for these traits among the parent lines.

Key words: Avena strigosa Schreb., hybrid populations, forage production, seed dormancy.

(') Recebido para publicação em 5 de outubro de 2009 e aceito em 19 de maio de 2010.

() Centro de Genômica e Fitomelhoramento, Departamento de Fitotecnia, Faculdade de Agronomia "Eliseu Maciel" (FAEM), Universidade Federal de Pelotas-UFPel, Campus Universitário, Caixa Postal 354, 96010-900 Pelotas (RS).

E-mail: gustavodasilveira.faem@gmail.com $\left(^{*}\right)$ Autor correspondente.

(3) Fundação Centro de Experimentação e Pesquisa Fecotrigo (CCGL Tec/ Fundacep), Caixa Postal 10, 98100-970 Cruz Alta (RS). 


\section{INTRODUÇÃO}

A aveia preta (Avena strigosa Schreb.) é uma gramínea de ciclo anual de estação fria largamente utilizada como espécie forrageira, em rotações de cultura ou para cobertura do solo, principalmente antecedendo a semeadura direta. É uma espécie rústica e menos exigente em solo em relação à cultura do trigo (DERSPCH e CALEGARI, 1985) e azevém (SALERMO e TCACENCO, 1985). Evidencia elevada adaptabilidade às condições de ambiente dos seguintes Estados: Rio Grande do Sul, Santa Catarina, Paraná, São Paulo e Mato Grosso do Sul (Derspch e CALEGARI, 1992), por possuir maior tolerância às condições de estresse abiótico e um sistema radicular agressivo que ajuda a manter as propriedades físicas do solo (FEDERIZZI e MunDSTOCK, 2004). O Rio Grande do Sul possui uma área de aproximadamente 3,3 milhões de hectares semeada com aveia preta, em contraste com os 321,4 mil hectares semeados com aveia branca (CONAB, 2008).

Apesar das extensas áreas cultivadas, os trabalhos voltados para o melhoramento da aveia preta ainda são muito reduzidos, com poucas cultivares disponibilizadas no mercado, sendo a denominada cultivar "Preta Comum" a mais utilizada pelos produtores, variedade que não possui identidade genética, mas tem elevada desuniformidade quanto aos caracteres ciclo vegetativo, estatura de plantas, potencial de produtividade de forragem e resistência a moléstias.

Devido a esta grande variabilidade presente na "Preta Comum", a maioria dos programas de melhoramento têm realizado seleções dentro desta cultivar para genótipos que expressam caracteres de interessee maior uniformidade. Um dos grandes desafios buscados pelos melhoristas é agrupar em um único genótipo a maior quantidade de caracteres desejáveis e, no caso de espécies forrageiras e de cobertura, a busca de produção de matéria seca aliada à qualidade de forragem superior.

Diante do crescimento da importância desta espécie no mercado, algumas instituições públicas e privadas têm iniciado programas de melhoramento voltados à obtenção de novos genótipos de aveia preta. A utilização de hibridações artificiais é uma das técnicas mais empregadas para obtenção de variabilidade genética no melhoramento de plantas, buscando reunir em um único genótipo alelos favoráveis presentes em cultivares comerciais, linhagens elites, plantas introduzidas ou em espécies relacionadas.

Outro problema observado nos genótipos de aveia preta é a presença de dormência nas sementes, pois como é uma espécie muito utilizada para fazer rotação de cultura com outras gramíneas de estação fria, a falta de seleção e o fato de ter se distribuído em vários ambientes sem manejo apropriado, assumiu característica de espécie invasora, principalmente nas lavouras de trigo, centeio e cevada. Segundo RIzZARDI e VARGAS (2005), o uso contínuo da aveia preta, associado a um desajuste das práticas de dessecação no momento da maturação das plantas, têm favorecido a formação de um banco de sementes dormentes no solo.

Diante destes aspectos, o objetivo do trabalho foi avaliar caracteres relacionados à produção de forragem e dormência de sementes em populações de aveia preta originadas de cruzamentos artificiais realizados entre linhagens derivadas da cultivar "Preta Comum" e cultivares comerciais da espécie.

\section{MATERIAL E MÉTODOS}

As populações híbridas incluídas na tabela 1 foram provenientes de cruzamentos realizados em 2005 e 2006, nos quais foram utilizados como genitores 10 linhagens e 3 cultivares de Avena strigosa (AGROZEBU, EMBRAPA140 e UPFA 21-Moreninha), cujas sementes tiveram procedência da Fundação Pró-Sementes de Apoio à Pesquisa, de Passo Fundo (RS). Devido à reduzida disponibilidade de sementes híbridas, em 2007, foi necessário o avanço de gerações (Figura 1), sem seleção artificial, para incrementar a quantidade de sementes disponíveis para o trabalho. Neste experimento, foram avaliadas plantas nas gerações F3 e F4, para as quais não havia qualquer informação sobre a expressão dos caracteres associados à produção de forragem, rendimento de sementes e nível de dormência nas sementes ao longo das gerações.

Dois experimentos foram desenvolvidos no invernode 2008, o primeiro com o objetivo de testar caracteres forrageiros e o segundo, para medir caracteres das sementes, como rendimento e nível de dormência. Ambos os experimentos foram instalados no município de Capão do Leão (RS), situado a $31^{\circ} 52^{\prime} 00^{\prime \prime}$ de latitude sul e $52^{\circ} 21^{\prime} 24^{\prime \prime}$ de longitude oeste, a uma altitude de 13,24 m. O clima, segundo a classificação de Köppen, é do tipo Cfa, com uma precipitação pluvial média anual de 1280,2 mm (Moreno, 1961). O solo é do tipo Argissolo distrófico de textura argilosa e relevo ondulado, com presença marcante do lençol freático próximo à superfície.

O primeiro experimento foi instalado na forma de blocos casualizados com três repetições. As unidades experimentais foram constituídas por populações híbridas e genitores fixos (tratamentos), em duas linhas de $3 \mathrm{~m}$ de comprimento, com espaçamento entre linhas de $0,20 \mathrm{~m}$, e densidade de 60 sementes viáveis por metro linear. Neste experimento, foram realizados três cortes, sendo o primeiro 45 dias após a semeadura, o segundo, 30 dias pós primeiro corte e o terceiro, 53 dias após o segundo corte; em cada corte foram avaliados os seguintes caracteres: 1) estatura de plantas (Estatura): mensurada antes de cada corte, computada pelo 
Tabela 1. Populações híbridas originárias de cruzamentos artificiais realizados nos anos de 2005 e 2006 e seus respectivos genitores. Capão do Leão, 2009

\begin{tabular}{|c|c|c|c|c|c|}
\hline \multicolumn{3}{|c|}{$\begin{array}{c}\text { Populações Híbridas F4 } \\
\text { (Cruzamento 2005) }\end{array}$} & \multicolumn{3}{|c|}{$\begin{array}{c}\text { Populações Híbridas F3 } \\
\text { (Cruzamento 2006) }\end{array}$} \\
\hline Populações & Genitor $q$ & Genitor $\widehat{\partial}$ & Populações & Genitor $\bigcirc$ & Genitor $\hat{\sigma}$ \\
\hline A03 & A94053 & A94112 & $\mathrm{AB}$ & Agrozebu & A94087 \\
\hline $\mathrm{C} 06$ & A94157 & Embrapa 140 & $\mathrm{AD}$ & Agrozebu & A94113 \\
\hline D02 & UPFA-21 & A94108 & $\mathrm{AE}$ & Agrozebu & A94053 \\
\hline D10 & A94069 & Agrozebu & $\mathrm{BD}$ & A94087 & A94113 \\
\hline D16 & Embrapa 140 & A94157 & $\mathrm{BF}$ & A94087 & A94157 \\
\hline D17 & A94113 & A94206 & $\mathrm{CA}$ & UPFA-21 & Agrozebu \\
\hline D18 & A94113 & Agrozebu & $\mathrm{CB}$ & UPFA-21 & A94087 \\
\hline D23 & Agrozebu & A94157 & $\mathrm{CF}$ & UPFA-21 & A94157 \\
\hline D27 & A94108 & A94157 & DA & A94113 & Agrozebu \\
\hline \multirow[t]{5}{*}{ D30 } & A94157 & A94113 & DB & A94113 & A94087 \\
\hline & & & $\mathrm{DF}$ & A94113 & A94157 \\
\hline & & & $\mathrm{EC}$ & A94053 & UPFA-21 \\
\hline & & & FB & A94157 & A94087 \\
\hline & & & $\mathrm{FC}$ & A94157 & UPFA-21 \\
\hline
\end{tabular}

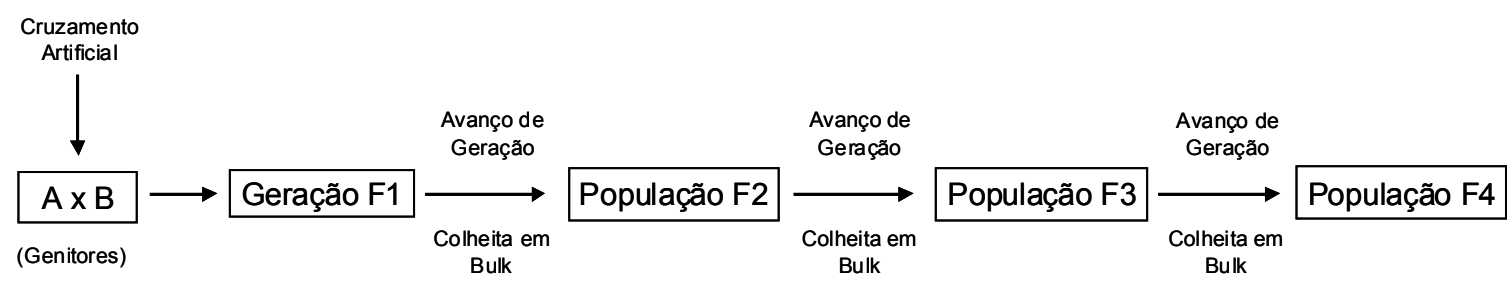

Figura 1. Representação esquemática do procedimento empregado na condução das populações de aveia preta, submetidas a cruzamentos artificiais. Capão do Leão, 2009.

comprimento do dossel, em centímetros, quantificada a partir da superfície do solo até a folha mais nova (primeiro e segundo cortes) ou folha bandeira, no caso do último corte; 2) rendimento de matéria seca (RendMS): a matéria verde foi colhida e pesada (g), com o corte de aproximadamente $8 \mathrm{~cm}$ acima da superfície do solo, e do total colhido foi extraída uma subamostra de aproximadamente 300 gramas, sendo secada em estufa a $60{ }^{\circ} \mathrm{C}$ por 72 horas para determinação da proporção de matéria seca, avaliada em $\mathrm{kg} \mathrm{ha}^{-1}$; 3) número de afilhos (Afilhos): avaliado por meio da contagem do número de afilhos em 0,5 metro linear logo após o corte, contado sempre no centro da parcela e 4) estande de plântulas: determinado por meio da contagem do número de plântulas emergidas em 0,5 metro linear de cada uma das duas linhas compondo cada parcela experimental, na área central da mesma, 28 dias após a semeadura.

A adubação e os tratos culturais foram feitos de acordo com as recomendações técnicas para a cultura da aveia no Rio Grande do Sul (CBPA, 2008), sendo aplicados $20 \mathrm{~kg} \mathrm{ha}^{-1}$ de nitrogênio após cada corte efetuado.

O segundo experimento foi estabelecido com o objetivo de avaliar o rendimento de sementes de cada população híbrida e seus genitores e o respectivo nível de dormência entre as diferentes constituições genéticas. Foi adotado o delineamento completamente casualizado, no qual cada unidade experimental era constituída por uma linha de $3 \mathrm{~m}$ de comprimento espaçada a 0,2 m com duas repetições, com densidade de 60 sementes viáveis por metro linear. O rendimento de sementes (RendS) foi avaliado por meio da trilha individual de cada linha, sendo expresso em $\mathrm{kg} \mathrm{ha}^{-1}$.

Com o intuito de avaliar o nível de dormência das sementes, trinta dias após a colheita foi efetuado um teste de germinação, conforme o estabelecido nas regras de análise de sementes para o gênero Avena L. (BRASIL, 1992), com quatro repetições por tratamento constituídas de 30 sementes por repetição, sob um delineamento inteiramente casualizado. Aos 5 e 10 dias ( $5 d$ e 10 d) foi contado o número de sementes germinadas, que tivessem gerado plântulas normais.

Os dados foram submetidos à análise de variância e a comparação de médias feita pelo teste de Scott e Knott a $1 \%$ por meio do programa computacional GENES (CRUZ, 2001). 


\section{RESULTADOS E DISCUSSÃO}

\section{Primeiro experimento}

Foi verificada diferença significativa para todos os caracteres avaliados, exceto para número de afilhos, no segundo corte, e estatura no terceiro corte (dados não apresentados). Esta diferença significativa apresentada entre os genitores para os caracteres testados pode ser considerada indicativa da variabilidade genética existente dentro da cultivar Preta Comum, devido a todas estas constituições genéticas serem provenientes de seleções dentro desta cultivar.

A análise de médias para o primeiro e segundo corte está contida na tabela 2, onde estão inseridos os resultados para os caracteres estatura de plantas, número de afilhos, rendimento de matéria seca e estande de plântulas.

Tabela 2. Análise de médias no primeiro e segundo cortes para estatura, afilhos, rendimento de matéria seca (RendMS) e estande (somente no primeiro corte), em genitores e populações híbridas de aveia preta. Capão do Leão, 2009

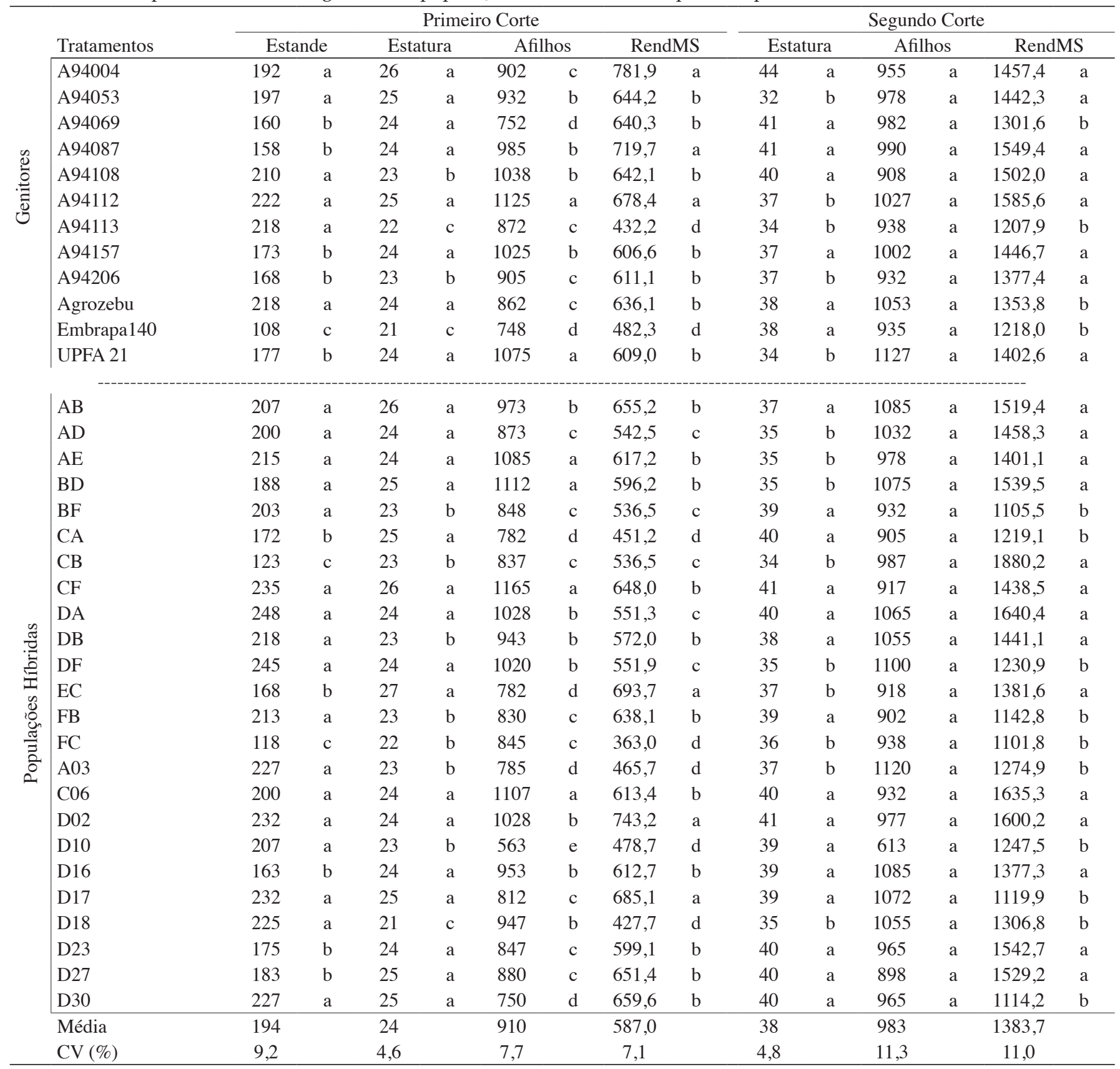

Médias seguidas da mesma letra não diferem pelo teste de Scott e Knott ao nível de 1\% de significância.

Estande $=\mathrm{n} .^{\circ}$ plantas $\mathrm{m}^{-2}$; Estatura = estatura do dossel antes do corte em $\mathrm{cm}$; Afilhos = número de afilhos $\mathrm{m}^{-2}$; Rendimento de matéria seca (RendMS) $=$ em Kg ha-1. 
O estande indica a capacidade dos diferentes genótipos germinarem, emergirem e se estabelecerem, caracterizando o vigor das plântulas. Segundo ElLIS (1992), aspectos como a germinação e o vigor podem influenciar o rendimento da cultura. Neste contexto, de acordo com a análise de médias, é possível verificar que para o caráter estande de plantas (Tabela 2) os genitores com desempenho superior foram A94004, A94053, A94108, A94112, A94113 e Agrozebu com 64, 66, 70, 74, 73 e $73 \%$ de plantas estabelecidas respectivamente, fator que pode influenciar diretamente o desenvolvimento inicial das plântulas com efeitos nos valores da produção de forragem no primeiro corte.

O estande inicial de plantas tem relação direta com a produção de matéria seca no primeiro corte. SCHUCH et al. (2000) verificaram que diferenças no nível de vigor e populações de plantas $\mathrm{m}^{-2}$ influenciaram diretamente na produção de matéria seca em períodos iniciais após a emergência das plântulas, até aproximadamente 75 dias após a emergência, tendo sua intensidade reduzida como crescimento das plantas. Nesta avaliação, as populações híbridas consideradas também evidenciaram diferenças para o caráter estande, alguns superando seus genitores, como o BF, CF, FB e C06; contudo, em grande parte das populações avaliadas não houve desempenho superior para o rendimento de matéria seca (RendMS), no primeiro corte, em relação a seus genitores, indicando que caracteres como estatura e número de afilhos podem estar influenciando no rendimento.

Somente duas populações D02 e D17, com o maior estande (Tabela 2) evidenciaram os maiores rendimento de forragem por ocasião do primeiro corte, 743,1 e 685,1 $\mathrm{kg} \mathrm{ha}^{-1} \mathrm{MS}$ respectivamente.

Diferenças significativas para a produção de matéria seca no primeiro corte foram detectadas (Tabela 2), para as populações D02, EC e D17, evidenciando desempenhosuperioràs demais populaçõeshíbridascom 743,1; 693,7 e 685,1 $\mathrm{kg} \mathrm{ha}^{-1}$ respectivamente, superando o desempenho de seus genitores. Esse resultado indica que a seleção destas constituições genéticas pode ser promissora para o caráter precocidade na produção de forragem. O anterior é particularmente importante para as populações D02 e D17, as quais constituíram uma geração mais avançada (F4), maior número de locos em homozigose. De acordo com CARÁmbula (1978) e CECATO (1998), a maior produção de forragem expressa por genótipos em estádio inicial poderá estar relacionada à maior precocidade de crescimento da parte aérea, complementada por bom desenvolvimento das raízes, favorecendo a absorção de água e nutrientes.

Outro fato a ser destacado em relação ao primeiro corte (Tabela 2), é a reduzida produção de afilhos da população EC (782 afilhos $\mathrm{m}^{-2}$ ), demonstrando que a produção de matéria seca pode estar relacionada também a outros caracteres, como a estatura, em que EC expressou a mais elevada, $27 \mathrm{~cm}$ antes do corte. Estatura de plantas mais elevada, associada a um elevado potencial de afilhamento em estádio inicial de crescimento são caracteres bastante desejados em espécies forrageiras, pois indica desenvolvimento mais precoce e acelerado, disponibilizando o primeiro corte ou pastejo antecipadamente. Segundo DenARDIN e KochHANn (1993), SANTos et al. (1990), o início do pastejo pode ser realizado a partir do afilhamento pleno, quando a aveia atingir em torno de $30 \mathrm{~cm}$.

Os genitores com maior rendimento de matéria seca no primeiro corte foram A94004, A94087 e A94112, com rendimentos de 781,8; 719,7 e 678,4 $\mathrm{kg} \mathrm{ha}^{-1}$ respectivamente. SCHEFFER-BASSO et al. (2001), avaliando genótipos de aveia para duplo-propósito, utilizaram dois genótipos de aveia preta como padrão (Preta Comum e Iapar 61), as quais desenvolveram 1137 e 1110 afilhos $\mathrm{m}^{-2}$ respectivamente, superando as aveias brancas utilizadas no trabalho, possibilitando aos autores estabelecer a hipótese de que o número de afilhos é um dos principais caracteres na produtividade de forragem.

O segundo corte foi realizado 30 dias após o primeiro, com as respectivas médias de desempenho das populações híbridas e genitores inseridos na tabela 2. Dos caracteres avaliados, somente o número de afilhos por metro quadrado não apresentou diferença significativa. Em relação aos genitores, somente os genótipos Agrozebu, A94069, Embrapa 140 e A94113 evidenciaram desempenho inferior às demais constituições genéticas avaliadas, com 1353,8; 1301,6; 1218,0 e $1207,9 \mathrm{~kg} \mathrm{ha}^{-1}$ de matéria seca respectivamente. Os demais genitores produziram em média $1450 \mathrm{~kg} \mathrm{ha}^{-1}$. Quanto às populações híbridas, muitos com médias elevadas, mas não diferindo dos genitores, exceto os genótipos $\mathrm{DA}$ e $\mathrm{AD}$ (recíprocos), que superaram seus genitores na produção de forragem. Estes dados permitem supor que a seleção de indivíduos dentro destas populações pode ser eficiente na obtenção de constituições genéticas superiores para produtividade de forragem.

O terceiro corte foi realizado 53 dias após o segundo. Em todos os caracteres avaliados houve diferença significativa, exceto estatura de plantas, indicando que o número de afilhos deve ter sido o principal caráter responsável pelas diferenças verificadas na produtividade de forragem. Os genótipos com produção de forragem superior também evidenciaram uma população de afilhos mais numerosa (Tabela 3).

Para a produtividade de matéria seca, as constituições genéticas com os melhores desempenhos foram A94157, Agrozebu, A94206 e A94069, entre os genitores, e D16, FC, CB, BD, D30, D17 e D27, entre as populações híbridas. Analisando os resultados 
Tabela 3. Análise de médias no terceiro corte e do total acumulado dos três cortes para estatura, afilhos e rendimento de matéria seca (RendMS), em genitores e populações híbridas de aveia preta. Capão do Leão, 2009

\begin{tabular}{|c|c|c|c|c|c|c|c|c|c|c|c|c|c|}
\hline \multirow{14}{*}{$\bar{P}$} & \multirow{3}{*}{$\begin{array}{l}\text { Tratamentos } \\
\text { A94004 }\end{array}$} & \multicolumn{6}{|c|}{ Terceiro Corte } & \multicolumn{6}{|c|}{ Total Cortes } \\
\hline & & \multicolumn{2}{|c|}{ Estatura } & \multicolumn{2}{|c|}{ Afilhos } & \multicolumn{2}{|c|}{ RendMS } & \multicolumn{2}{|c|}{ Estatura } & \multicolumn{2}{|c|}{ Afilhos } & \multicolumn{2}{|c|}{ RendMS } \\
\hline & & 50 & $\mathrm{a}$ & 640 & $\mathrm{~b}$ & 2078,5 & $\mathrm{~b}$ & 40 & $\mathrm{a}$ & 832 & $\mathrm{~b}$ & 4317,8 & $\mathrm{c}$ \\
\hline & A94053 & 51 & $\mathrm{a}$ & 990 & $\mathrm{a}$ & 2597,0 & $\mathrm{~b}$ & 36 & b & 867 & $\mathrm{~b}$ & 4683,4 & $\mathrm{~b}$ \\
\hline & A94069 & 52 & $\mathrm{a}$ & 938 & $\mathrm{a}$ & 2881,0 & $\mathrm{a}$ & 39 & $\mathrm{a}$ & 824 & b & 4823,1 & $\mathrm{~b}$ \\
\hline & A94087 & 55 & $\mathrm{a}$ & 895 & $\mathrm{a}$ & 2009,8 & b & 40 & $\mathrm{a}$ & 957 & $\mathrm{a}$ & 4278,8 & $\mathrm{c}$ \\
\hline & A94108 & 49 & $\mathrm{a}$ & 830 & $\mathrm{~b}$ & 1905,4 & $\mathrm{~b}$ & 37 & b & 926 & $\mathrm{a}$ & 4049,5 & $\mathrm{c}$ \\
\hline & A94112 & 51 & $\mathrm{a}$ & 1150 & $\mathrm{a}$ & 2120,6 & b & 38 & b & 1101 & $\mathrm{a}$ & 4384,6 & $\mathrm{c}$ \\
\hline & A94113 & 51 & $\mathrm{a}$ & 748 & $\mathrm{~b}$ & 2415,1 & b & 36 & b & 853 & $\mathrm{~b}$ & 4055,1 & $\mathrm{c}$ \\
\hline & A94157 & 52 & $\mathrm{a}$ & 1047 & $\mathrm{a}$ & 3653,9 & $\mathrm{a}$ & 38 & b & 1024 & $\mathrm{a}$ & 5707,2 & $\mathrm{a}$ \\
\hline & A94206 & 53 & $\mathrm{a}$ & 932 & $\mathrm{a}$ & 2914,2 & a & 36 & b & 856 & b & 4902,6 & $\mathrm{~b}$ \\
\hline & Agrozebu & 53 & $\mathrm{a}$ & 907 & $\mathrm{a}$ & 2967,3 & $\mathrm{a}$ & 38 & b & 941 & $\mathrm{a}$ & 4957,2 & $\mathrm{~b}$ \\
\hline & Embrapa140 & 53 & $\mathrm{a}$ & 677 & $\mathrm{~b}$ & 1841,7 & b & 38 & b & 787 & $\mathrm{~b}$ & 3541,9 & $\mathrm{c}$ \\
\hline & UPFA 21 & 52 & $\mathrm{a}$ & 992 & $\mathrm{a}$ & 2222,0 & b & 37 & b & 1064 & a & 4233,5 & $\mathrm{c}$ \\
\hline \multirow{26}{*}{ 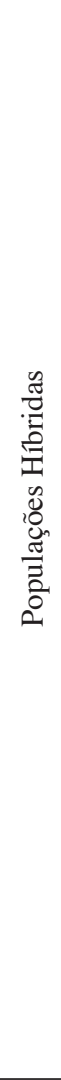 } & $\mathrm{AB}$ & 51 & $\mathrm{a}$ & 997 & $\mathrm{a}$ & 2189,2 & b & 38 & b & 1018 & $\mathrm{a}$ & 4363,8 & $\mathrm{c}$ \\
\hline & AD & 55 & $\mathrm{a}$ & 1045 & $\mathrm{a}$ & 1972,9 & b & 38 & b & 983 & $\mathrm{a}$ & 3973,8 & $\mathrm{c}$ \\
\hline & $\mathrm{AE}$ & 51 & $\mathrm{a}$ & 773 & $\mathrm{~b}$ & 2545,1 & b & 37 & b & 946 & $\mathrm{a}$ & 4563,5 & c \\
\hline & BD & 53 & $\mathrm{a}$ & 975 & $\mathrm{a}$ & 2894,7 & $\mathrm{a}$ & 37 & b & 1054 & $\mathrm{a}$ & 5030,4 & b \\
\hline & $\mathrm{BF}$ & 54 & $\mathrm{a}$ & 908 & $\mathrm{a}$ & 2565,8 & b & 38 & $\mathrm{a}$ & 896 & $\mathrm{~b}$ & 4207,7 & $\mathrm{c}$ \\
\hline & $\mathrm{CA}$ & 54 & $\mathrm{a}$ & 892 & $\mathrm{a}$ & 2249,7 & b & 40 & a & 859 & $\mathrm{~b}$ & 3920,1 & $\mathrm{c}$ \\
\hline & $\mathrm{CB}$ & 55 & $\mathrm{a}$ & 898 & $\mathrm{a}$ & 2985,6 & $\mathrm{a}$ & 37 & b & 874 & $\mathrm{a}$ & 5402,2 & $\mathrm{a}$ \\
\hline & $\mathrm{CF}$ & 53 & $\mathrm{a}$ & 750 & b & 2112,6 & b & 40 & $\mathrm{a}$ & 944 & $\mathrm{a}$ & 4199,1 & $\mathrm{c}$ \\
\hline & DA & 53 & $\mathrm{a}$ & 1007 & $\mathrm{a}$ & 2462,0 & b & 39 & $\mathrm{a}$ & 1033 & $\mathrm{a}$ & 4653,7 & b \\
\hline & DB & 52 & $\mathrm{a}$ & 962 & $\mathrm{a}$ & 2543,4 & b & 38 & b & 987 & $\mathrm{a}$ & 4556,4 & $\mathrm{c}$ \\
\hline & DF & 53 & $\mathrm{a}$ & 895 & $\mathrm{a}$ & 2457,6 & b & 37 & b & 1005 & $\mathrm{a}$ & 4240,4 & $\mathrm{c}$ \\
\hline & EC & 55 & $\mathrm{a}$ & 743 & b & 2408,3 & b & 40 & $\mathrm{a}$ & 814 & b & 4483,2 & c \\
\hline & FB & 54 & $\mathrm{a}$ & 770 & b & 2258,9 & b & 39 & $\mathrm{a}$ & 834 & b & 4039,8 & $\mathrm{c}$ \\
\hline & FC & 55 & $\mathrm{a}$ & 983 & $\mathrm{a}$ & 3136,6 & a & 38 & b & 856 & b & 4601,4 & $\mathrm{c}$ \\
\hline & A03 & 55 & $\mathrm{a}$ & 898 & $\mathrm{a}$ & 2362,8 & b & 38 & b & 934 & $\mathrm{a}$ & 4103,4 & $\mathrm{c}$ \\
\hline & $\mathrm{C} 06$ & 52 & $\mathrm{a}$ & 878 & $\mathrm{a}$ & 2273,2 & b & 39 & $\mathrm{a}$ & 972 & $\mathrm{a}$ & 4521,9 & $\mathrm{c}$ \\
\hline & D02 & 52 & $\mathrm{a}$ & 635 & b & 2361,4 & b & 39 & $\mathrm{a}$ & 880 & b & 4704,8 & b \\
\hline & D10 & 51 & $\mathrm{a}$ & 408 & b & 1973,0 & b & 38 & b & 528 & $\mathrm{c}$ & 3699,3 & c \\
\hline & D16 & 55 & $\mathrm{a}$ & 1000 & a & 3617,8 & $\mathrm{a}$ & 40 & $\mathrm{a}$ & 999 & $\mathrm{a}$ & 5607,2 & $\mathrm{a}$ \\
\hline & D17 & 55 & $\mathrm{a}$ & 1115 & $\mathrm{a}$ & 2719,7 & $\mathrm{a}$ & 40 & $\mathrm{a}$ & 999 & $\mathrm{a}$ & 4524,6 & $\mathrm{c}$ \\
\hline & D18 & 54 & $\mathrm{a}$ & 1038 & $\mathrm{a}$ & 2510,0 & b & 37 & b & 1013 & $\mathrm{a}$ & 4244,4 & $\mathrm{c}$ \\
\hline & D23 & 51 & $\mathrm{a}$ & 1022 & $\mathrm{a}$ & 2568,6 & b & 39 & $\mathrm{a}$ & 944 & $\mathrm{a}$ & 4710,4 & b \\
\hline & D27 & 54 & $\mathrm{a}$ & 990 & $\mathrm{a}$ & 2769,0 & $\mathrm{a}$ & 40 & $\mathrm{a}$ & 923 & $\mathrm{a}$ & 4949,6 & b \\
\hline & D30 & 55 & $\mathrm{a}$ & 1033 & $\mathrm{a}$ & 2803,2 & $\mathrm{a}$ & 40 & $\mathrm{a}$ & 916 & $\mathrm{a}$ & 4577,1 & $\mathrm{c}$ \\
\hline & Média & 53 & & 880 & & 2546,5 & & 38 & & 2773 & & 4517,2 & \\
\hline & CV (\%) & 5,0 & & 13,9 & & 14,6 & & 2,9 & & 7,8 & & 8,5 & \\
\hline
\end{tabular}

Médias seguidas da mesma letra não diferem pelo teste de Scott e Knott ao nível de 1\% de significância.

Estatura = estatura do dossel antes do corte em $\mathrm{cm}$; Afilhos = número de afilhos $\mathrm{m}^{-2}$; Rendimento de matéria seca $($ RendMS $)=$ em Kg ha-1 .

individuais dos três cortes, apresentado nas tabelas 2 e 3, é possível verificar que as constituições genéticas A94069, Agrozebu, FC e D30 que produziram maior matéria seca no terceiro corte, porém menor produção no primeiro e segundo cortes. Ao contrário, aquelas constituições genéticas que produziram mais matéria seca no primeiro e segundo cortes (A94004, A94087, A94112, EC e D02) foram os que menos produziram no terceiro corte. Estes resultados revelam que genótipos com maior produtividade nos cortes iniciais são mais precoces em relação àqueles que têm seu maior potencial produtivo em cortes posteriores. Segundo Cесато (1998), este resultado tem grande importância em espécies forrageiras, pois do ponto de vista técnico, ao misturar duas cultivares de ciclos distintos, sendo uma precoce e uma tardia, favorecerá o produtor, pois além de aumentar a produtividade da forragem, prolongará o ciclo produtivo da pastagem. Essa disponibilidade 
de variabilidade para o caráter comprimento de ciclo é extremamente importante em qualquer programa de melhoramento de espécies forrageiras.

De acordo com os resultados anotados para o total acumulado dos três cortes (Tabela 3), ocorreu diferença significativa para todos os caracteres avaliados. Em média, os genótipos estavam com estatura de $38 \mathrm{~cm}$ no momento do corte. Quanto ao caráter produtividade de forragem, a linhagem A94157 foi a que expressou maior produção total, com $5707,2 \mathrm{~kg} \mathrm{ha}^{-1}$, superando as demais. Entre as populações híbridas, as que se destacaram foram D16 e CB, com 5607,2 e 5402,2 kg ha ${ }^{-1}$ de matéria seca respectivamente. Estas constituições genéticas que obtiveram maior produção total de matéria seca foram as de melhor desempenho, principalmente no segundo e terceiro cortes, tanto para forragem como para produção de afilhos, indicando que a taxa de produção de afilhos foi mantida do segundo para o terceiro corte. Em trabalhos realizados por outros autores, porém com outros genótipos, ocorreram resultados semelhantes (Fontaneli e Piovezan, 1990; SchefFer-Basso et al., 2001).

\section{Segundo experimento}

Para o caráter rendimento de sementes (RendS), foi possível detectar diferenças significativas entre os tratamentos, evidenciando uma possível variabilidade genética entre as constituições genéticas testadas, demonstrando que a técnica de hibridação artificial foi eficiente no aumento de variabilidade deste caráter. Esse fato revela a importância de promover pesquisa nestes genótipos, buscando novas cultivares, com maior uniformidade em caracteres de importância agronômica.

Os dados do comportamento médios das constituições genéticas relacionadas ao rendimento de sementes estão inseridos na tabela 4 . Este é um caráter de extrema importância e altamente buscado pelos melhoristas, sendo almejada a obtenção de genótipos de elevada produtividade e adequada qualidade das sementes. Em relação aos genitores avaliados, A94069 revelou maior produtividade de sementes, com $894,7 \mathrm{~kg}$ ha $^{-1}$ (Tabela 4), sendo este o melhor desempenho entre todos os genótipos avaliados. Outros genitores com bom desempenho foram A94108 e Embrapa 140, com rendimentos de 801,1 e $800,7 \mathrm{~kg} \mathrm{ha}^{-1}$ respectivamente. Entre as populações híbridas, podem ser destacados EC, C06, D16, D10, A03 e D23, com rendimentos de, respectivamente, 761,2, 740,3, 699,3, 652,1, 595,9, 575,3 e 595,9 $\mathrm{kg} \mathrm{ha}^{-1}$. Trabalhos de outros autores revelaram grande divergência para o caráter rendimento de sementes de aveia preta, variando desde $194 \mathrm{~kg} \mathrm{ha}^{-1}$, da cultivar UPFA 21 (Floss et al., 2008), até $1375 \mathrm{~kg} \mathrm{ha}^{-1}$, da Preta Comum (OliverRa et al., 2008). Estes resultados indicam reduzida pesquisa sobre o caráter rendimento de grãos e revelam que maiores pressões de seleção são fundamentais para a obtenção de genótipos superiores.

Além disso, os três genótipos com maior produção de matéria seca total (A94157, CB e D16), conforme a tabela 3, não foram destaques para a produção de sementes, indicando haver uma distinta adaptação entre a capacidade do genótipo para produção de forragem ou produção de sementes. Pequena exceção para a população híbrida D16 com produção de sementes de $699 \mathrm{~kg} \mathrm{ha}^{-1}$.

Quanto ao caráter dormência de sementes, as avaliações foram realizadas através de duas contagens, aos cinco dias e 10 dias após as sementes dos genitores e populações híbridas terem sido colocados no germinador. Foi detectada interação significativa entre tratamento e períodos, indicando que o padrão de germinação ao longo dos dois períodos de contagem não foi o mesmo para todos os genótipos avaliados (dados não apresentados). As análises evidenciaram que o período de cinco dias expressou maior importância em relação à porcentagem de sementes germinadas. Moliterno (2008), avaliando linhagens de aveia preta para o caráter dormência nas sementes, concluiu que a maior proporção de plântulas formadas provinha de sementes que germinavam nos primeiros cinco dias, sugerindo possível associação entre vigor de sementes e baixo nível de dormência.

O teste de germinação realizado 30 dias após a colheita das sementes pode fornecer uma informação importante, pois grande número de espécies possui um nível mais elevado de dormência nas sementes logo após a colheita, a qual vai se reduzindo com o passar do tempo, sendo este período denominado por alguns autores como "maturação pós-colheita" (BEWLEY, 1997; Foley e Fennimore, 1998; Leubner-MetzGer, 2003). Diante deste conceito, e considerando o curto espaço de tempo entre a colheita e o teste de germinação, pode ser considerado que a maturação pós-colheita ocorreu durante um período relativamente curto para estimular a superação total da dormência naqueles genótipos com maior nível do caráter (Finch-SAVAGE e LeUBNER-METZGER, 2006).

Os genitores com desempenhos superiores no teste de germinação avaliados aos cinco dias (Tabela 4) foram: A94004, Agrozebu e A94112 com 85\%, 76\% e $75 \%$ de germinação respectivamente, enquanto para os híbridos foram CF, D30, BD e D17 com $85 \%$, 85\%, $78 \%$ e $75 \%$ respectivamente, todos eles superando o desempenho de seus genitores. Resultado bastante expressivo, visto que estas constituições genéticas não foram submetidas à pressão de seleção para o caráter ausência de dormência nas sementes, com destaque para os genótipos D30 e D17 que, além de terem 
Tabela 4. Análise de médias para rendimento de sementes (RendS) e teste de germinação avaliado aos 5 e 10 dias (5d e $10 \mathrm{~d}$ ) respectivamente, em genitores e populações híbridas de aveia preta. Capão do Leão, 2009

\begin{tabular}{|c|c|c|c|c|c|c|c|c|c|}
\hline & \multirow{2}{*}{\begin{tabular}{|l|} 
Tratamentos \\
A94004
\end{tabular}} & \multicolumn{2}{|c|}{ RendS } & \multicolumn{2}{|c|}{ Germ 5d } & \multicolumn{2}{|c|}{ Germ 10d } & \multicolumn{2}{|c|}{ Germ Total } \\
\hline \multirow{12}{*}{$\begin{array}{l}\tilde{0} \\
\stackrel{0}{0} \\
. \\
0 \\
0 \\
0\end{array}$} & & 649,3 & $\mathrm{c}$ & 85,1 & $\mathrm{a}$ & 4,2 & $\mathrm{~b}$ & 85,8 & $\mathrm{a}$ \\
\hline & A94053 & 293,8 & $\mathrm{f}$ & 31,7 & d & 5,3 & $\mathrm{~b}$ & 35,0 & $\mathrm{~d}$ \\
\hline & A94069 & 894,7 & a & 52,5 & $\mathrm{c}$ & 5,3 & $\mathrm{~b}$ & 55,0 & $\mathrm{c}$ \\
\hline & A94087 & 603,1 & $\mathrm{c}$ & 39,2 & $\mathrm{c}$ & 12,7 & $\mathrm{a}$ & 46,7 & $\mathrm{c}$ \\
\hline & A94108 & 801,1 & $\mathrm{~b}$ & 38,3 & $\mathrm{c}$ & 3,3 & $\mathrm{~b}$ & 40,9 & d \\
\hline & A94112 & 321,4 & $\mathrm{f}$ & 75,1 & $\mathrm{a}$ & 2,8 & $\mathrm{~b}$ & 75,8 & $\mathrm{a}$ \\
\hline & A94113 & 86,4 & $\mathrm{~h}$ & 29,2 & $\mathrm{~d}$ & 2,2 & $\mathrm{~b}$ & 30,9 & $\mathrm{~d}$ \\
\hline & A94157 & 518,9 & d & 49,2 & $\mathrm{c}$ & 4,0 & $\mathrm{~b}$ & 50,8 & $\mathrm{c}$ \\
\hline & A94206 & 482,3 & $\mathrm{~d}$ & 66,7 & $\mathrm{~b}$ & 9,1 & $\mathrm{~b}$ & 70,0 & $\mathrm{~b}$ \\
\hline & Agrozebu & 305,8 & $\mathrm{f}$ & 75,8 & $\mathrm{a}$ & 11,9 & $\mathrm{a}$ & 78,3 & $\mathrm{a}$ \\
\hline & Embrapa140 & 800,7 & $\mathrm{~b}$ & 71,7 & $\mathrm{~b}$ & 14,3 & $\mathrm{a}$ & 75,8 & a \\
\hline & UPFA 21 & 351,4 & $\mathrm{e}$ & 56,7 & $\mathrm{~b}$ & 7,7 & $\mathrm{~b}$ & 60,0 & $\mathrm{~b}$ \\
\hline \multirow{26}{*}{ 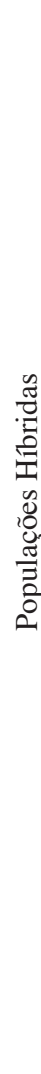 } & $\mathrm{AB}$ & 82,0 & $\mathrm{~h}$ & 16,7 & d & 3,1 & $\mathrm{~b}$ & 19,2 & $\mathrm{~d}$ \\
\hline & $\mathrm{AD}$ & 127,0 & $\mathrm{~g}$ & 66,7 & $\mathrm{~b}$ & 10,3 & $\mathrm{~b}$ & 69,2 & $\mathrm{~b}$ \\
\hline & $\mathrm{AE}$ & 320,3 & $\mathrm{f}$ & 47,5 & $\mathrm{c}$ & 9,9 & $\mathrm{~b}$ & 52,5 & $\mathrm{c}$ \\
\hline & BD & 200,8 & $\mathrm{~g}$ & 78,3 & $\mathrm{a}$ & 6,7 & $\mathrm{~b}$ & 80,0 & $\mathrm{a}$ \\
\hline & BF & 384,3 & $\mathrm{e}$ & 65,8 & $\mathrm{~b}$ & 10,2 & $\mathrm{~b}$ & 69,2 & $\mathrm{~b}$ \\
\hline & $\mathrm{CA}$ & 270,5 & $\mathrm{f}$ & 57,5 & $\mathrm{~b}$ & 4,7 & $\mathrm{~b}$ & 60,0 & $\mathrm{~b}$ \\
\hline & $\mathrm{CB}$ & 146,1 & $\mathrm{~g}$ & - & - & - & - & - & - \\
\hline & $\mathrm{CF}$ & 480,8 & $\mathrm{~d}$ & 85,1 & $\mathrm{a}$ & 20,8 & $\mathrm{a}$ & 88,3 & $\mathrm{a}$ \\
\hline & DA & 412,8 & e & 70,1 & $\mathrm{~b}$ & 1,8 & $\mathrm{~b}$ & 70,9 & $\mathrm{~b}$ \\
\hline & DB & 284,5 & $\mathrm{f}$ & 71,7 & $\mathrm{~b}$ & 6,9 & $\mathrm{~b}$ & 73,4 & $\mathrm{~b}$ \\
\hline & DF & 86,6 & $\mathrm{~h}$ & 61,7 & $\mathrm{~b}$ & 5,4 & $\mathrm{~b}$ & 63,3 & $\mathrm{~b}$ \\
\hline & EC & 761,2 & $\mathrm{~b}$ & 67,5 & $\mathrm{~b}$ & 5,5 & $\mathrm{~b}$ & 70,0 & $\mathrm{~b}$ \\
\hline & FB & 364,2 & $\mathrm{e}$ & 65,8 & $\mathrm{~b}$ & 2,3 & $\mathrm{~b}$ & 66,7 & $\mathrm{~b}$ \\
\hline & FC & 347,0 & e & 44,2 & $\mathrm{c}$ & 6,1 & $\mathrm{~b}$ & 47,5 & $\mathrm{c}$ \\
\hline & A03 & 575,3 & $\mathrm{c}$ & 31,7 & $\mathrm{~d}$ & 9,6 & $\mathrm{~b}$ & 36,7 & $\mathrm{~d}$ \\
\hline & C06 & 740,3 & $\mathrm{~b}$ & 50,8 & $\mathrm{c}$ & 11,7 & $\mathrm{a}$ & 56,7 & $\mathrm{c}$ \\
\hline & D02 & 513,8 & $\mathrm{~d}$ & 70,8 & $\mathrm{~b}$ & 14,9 & $\mathrm{a}$ & 75,0 & $\mathrm{a}$ \\
\hline & D10 & 652,1 & $\mathrm{c}$ & 68,3 & $\mathrm{~b}$ & 25,9 & $\mathrm{a}$ & 76,7 & $\mathrm{a}$ \\
\hline & D16 & 699,3 & $\mathrm{~b}$ & 69,2 & $\mathrm{~b}$ & 0,0 & $\mathrm{~b}$ & 69,2 & $\mathrm{~b}$ \\
\hline & D17 & 349,0 & e & 75,1 & $\mathrm{a}$ & 8,9 & $\mathrm{~b}$ & 78,3 & $\mathrm{a}$ \\
\hline & D18 & 251,7 & $\mathrm{f}$ & 60,1 & $\mathrm{~b}$ & 14,7 & $\mathrm{a}$ & 65,9 & $\mathrm{~b}$ \\
\hline & D23 & 595,9 & $\mathrm{c}$ & 31,7 & $\mathrm{~d}$ & 7,7 & $\mathrm{~b}$ & 36,7 & $\mathrm{~d}$ \\
\hline & D27 & 795,3 & $\mathrm{~b}$ & 67,5 & $\mathrm{~b}$ & 0,0 & $\mathrm{~b}$ & 67,5 & $\mathrm{~b}$ \\
\hline & D30 & 266,7 & $\mathrm{f}$ & 85,1 & $\mathrm{a}$ & 25,0 & $\mathrm{a}$ & 87,5 & $\mathrm{a}$ \\
\hline & Média & 415,1 & & 60,0 & & 9,0 & & 62,9 & \\
\hline & $\mathrm{CV}(\%)$ & 17,2 & & 9,7 & & 35,8 & & 16,5 & \\
\hline
\end{tabular}

Médias seguidas da mesma letra não diferem pelo teste de Scott e Knott ao nível de 1\% de significância.

Rendimento de sementes $($ RendS $)=\mathrm{em} \mathrm{kg} \mathrm{ha}^{-1}$; Germ $5 \mathrm{~d}=$ teste de germinação avaliado aos 5 dias, em porcentagem; Germ $10 \mathrm{~d}=$ teste de germinação avaliado aos 10 dias, em porcentagem; Germ Total = teste de germinação total $(5 \mathrm{~d}+10 \mathrm{~d})$, em porcentagem . - = Reduzido número de sementes para realização do teste.

superado o desempenho de seus genitores, estão em uma geração mais avançada (F4), isto é, com maior nível de homozigose entre os alelos, indicando que a seleção de plantas desta população, oriundas de sementes germinadas nos primeiros cinco dias, poderia ser mais eficiente na obtenção de ganho genético para o caráter.

No entanto, deve-se ter cuidado na seleção para ausência de dormência, pois alguns autores, para outras espécies, relataram que este é um caráter quantitativo, podendo haver grande influência do ambiente e, assim, reduzir a eficiência da seleção (BASKIN e BASKIN, 2004; Benech-Arnold et al., 2000). Foley e Fennimore (1998), trabalhando com Avena fatua L., espécie considerada como modelo para o estudo da dormência, observaram que a herdabilidade para este caráter foi de aproximadamente $50 \%$ (de origem genética) sendo os outros $50 \%$ de origem do ambiente. 
Tabela 5. Estimativas das variâncias fenotípicas $\left(\mathrm{V}_{\mathrm{f}}\right)$, genotípicas $\left(\mathrm{V}_{\mathrm{g}}\right)$, ambientais $\left(\mathrm{V}_{\mathrm{e}}\right)$, herdabilidade $\left(\mathrm{h}^{2}\right)$, coeficiente de variação genético $\left(\mathrm{CV}_{\mathrm{g}}\right)$, coeficiente de variação ambiental $\left(\mathrm{CV}_{\mathrm{e}}\right)$ e razão entre coeficiente de variação genético e ambiental $\left(\mathrm{CV}_{\mathrm{g}} / \mathrm{CV}_{\mathrm{e}}\right)$, para os caracteres rendimento de matéria seca (RendMS), rendimento de sementes (RendS) e teste de germinação (Germ). Capão do Leão, 2009

\begin{tabular}{|c|c|c|c|c|}
\hline Parâmetros & $\begin{array}{c}\text { Primeiro Corte } \\
\text { RendMS }\end{array}$ & $\begin{array}{c}\text { Segundo corte } \\
\text { RendMS }\end{array}$ & $\begin{array}{l}\text { Terceiro corte } \\
\text { RendMS }\end{array}$ & $\begin{array}{c}\text { Total cortes } \\
\text { RendMS }\end{array}$ \\
\hline $\mathrm{V}_{\mathrm{g}}$ & 8186,2 & 22872,6 & 151219,0 & 175284,9 \\
\hline$V_{f}^{b}$ & 8773,0 & 30652,5 & 197299,13 & 224647,3 \\
\hline $\mathrm{V}_{\mathrm{e}}$ & 586,8 & 7779,9 & 46080,1 & 49362,4 \\
\hline$h^{2}$ & 93,3 & 74,6 & 76,6 & 78,0 \\
\hline $\mathrm{CV}_{\mathrm{g}}$ & 15,4 & 10,3 & 15,3 & 9,3 \\
\hline $\mathrm{CV}_{\mathrm{e}}^{\circ}$ & 7,2 & 11,0 & 14,6 & 8,5 \\
\hline \multirow[t]{2}{*}{$\mathrm{CV}_{\mathrm{g}} / \mathrm{CV}_{\mathrm{e}}$} & 2,2 & 1,0 & 1,1 & 1,1 \\
\hline & RendS & Germ 5d & Germ 10d & Germ Total \\
\hline $\mathrm{V}_{\mathrm{g}}$ & 45835,0 & 286,2 & 22,2 & 271,9 \\
\hline$V_{f}^{b}$ & 57150,1 & 313,9 & 41,9 & 298,8 \\
\hline $\mathrm{V}_{\mathrm{e}}$ & 11315,2 & 27,7 & 19,7 & 26,9 \\
\hline$h^{2}$ & 80,2 & 91,2 & 53,0 & 91,0 \\
\hline $\mathrm{CV}_{\mathrm{g}}$ & 51,6 & 28,2 & 54,0 & 26,2 \\
\hline $\mathrm{CV}_{\mathrm{e}}^{\circ}$ & 36,9 & 17,6 & 101,7 & 16,5 \\
\hline $\mathrm{CV}_{\sigma} / \mathrm{CV}_{e}$ & 1,4 & 1,6 & 0,5 & 1,6 \\
\hline
\end{tabular}

RendMS = Rendimento de matéria seca; RendS = Rendimento de sementes; Germ 5d = teste de germinação avaliado aos 5 dias; Germ $10 \mathrm{~d}$ = teste de germinação avaliado aos 10 dias; Germ Total = teste de germinação total $(5 \mathrm{~d}+10 \mathrm{~d})$.

Ainda na tabela 4 está incluído o teste de germinação avaliado 10 dias após as sementes terem sido colocadas no germinador. Este período revelou valores complementares no nível de germinação para o período inicial de cinco dias, resultado semelhante ao avaliado por Moliterno (2008). Entre os genótipos avaliados os que tiveram desempenho superior foram: Embrapa 140, A94087 e Agrozebu para os genitores e D10, D30, CF, D02, D18 e C06 entre as populações híbridas com média de 17\% de plântulas germinadas, no período de 10 dias.

Para germinação total (Tabela 4), os genótipos com maior percentual de germinação coincidiram com os apresentados no período de cinco dias, com exceção da Embrapa 140, D02 e D10, resultado que corrobora a importância do teste inicial em relação ao realizado posteriormente.

Na tabela 5, são apresentados os parâmetros genéticos para alguns caracteres de importância em aveia preta. Os valores de herdabilidade foram medianamente altos para todos os caracteres avaliados, exceto para o teste de germinação aos 10 dias (54\%). Para RendMS no primeiro corte, Germ $5 \mathrm{~d}$ e RendS, os valores de herdabilidade foram de 93,3\%, 91,2\% e $80,2 \%$ respectivamente, indicando que a seleção direta para estes caracteres revelam condições favoráveis em termos de ganho genético imediato. Estes resultados de elevada magnitude podem ser decorrentes da grande variabilidade genética apresentadas por estes caracteres e pela pequena pressão de seleção exercida sobre eles.

Quanto à relação $\mathrm{CV}_{\mathrm{g}} / \mathrm{CV}_{\mathrm{e}^{\prime}}$ foram anotados valores maiores que a unidade para todos os caracteres, exceto para Germ 10d e RendMS, no segundo corte, indicando que métodos relativamente simples de seleção nestes caracteres podem ser promissores para obtenção de genótipos superiores (CRUZ et al., 2004).

\section{CONCLUSÕES}

1. A hibridação artificial intensifica a variabilidade genética e melhora a expressão dos caracteres estande inicial, estatura de plantas, número de afilhos, rendimento de forragem e grãos e reduzida expressão de dormência de sementes em aveia preta.

2. Os parâmetros estande e estatura de plantas têm importância diferenciada ao longo dos diferentes cortes e na produção total acumulada de forragem, evidenciando efeitos de compensação na expressão da variável produção de forragem.

3. O período inicial de cinco dias é o mais importante no teste de germinação, sendo suficiente para discriminar constituições genéticas com maior ou menor grau de dormência nas sementes.

\section{REFERÊNCIAS}

BASKIN, C.C.; BASKIN, J.M. A classification system for seed dormancy. Seed Science Research, v.14, p.1-16, 2004. 
BENECH-ARNOLD, R.L.; SÁNCHEZ, R.A.; FORCELLA, F. et al. Environmental control of dormancy in weed seed banks in soil. Field Crops Research, v.67, p.105-122, 2000.

BEWLEY, J. D. Seed germination and dormancy. Plant Cell, v.9, p.1055-1066. 1997.

BRASIL. Ministério da Agricultura e Reforma Agrária. Regras para análise de sementes. Brasília: SNDA/DNDV/ CLAV, 1992. 365p

CARÁMBULA, M. Producción y manejo de pasturas sembradas. Montevideo: Hemisferio Sur, 1978. 664p.

CECATO, U. Avaliações de cultivares e linhagens de aveia (Avena spp.). Acta Scientiarum, v.20, p.347-354, 1998.

CONAB - Companhia Nacional de Abastecimento. Disponível em: <http:/ / www.conab.gov.br>. Acesso em: 28 jul. 2008.

CBPA - Comissão Brasileira de Pesquisa de Aveia. Indicações técnicas para cultura da aveia. Comissão Brasileira de Pesquisa de Aveia - Guarapuava: A Comissão: Fundação Agrária de Pesquisa Agropecuária, 2006. 82p.

CRUZ, C.D. Programa genes: aplicativo computacional em genética e estatística. Viçosa: UFV, 2001. 648p.

CRUZ, C.D.; REGAZZI, A.J.; CARNEIRO, P.C.S. Modelos biométricos aplicados ao melhoramento genético. Viçosa: UFV, 2004. 480 p.

DENARDIN, J.E.; KOCHHANN, R.A. Requisitos para implantação e manutenção do sistema plantio direto. In: EMBRAPA, CNPT. Plantio direto no Brasil. Passo Fundo, 1993. p.19-27.

DERPSCH, R.; CALEGARI, A. Guia de plantas para adubação verde de inverno. Londrina: IAPAR, 1985. 96p. (IAPAR, Documento, 9)

DERPSCH, R.; CALEGARI, A. Plantas para adubação verde de inverno. Londrina: IAPAR, 1992. 80p. (Circular, 73)

ELLIS, R.H. Seed and seedling vigour in relation to crop growth and yield. Plant Growth Regulation, v.11, p.249$255,1992$.

FEDERIZZI, L.C.; MUNDSTOCK, C.M. Chapter IV-Fodder oats: an overview for South America. In: SUTTIES, J.M.; REYNOLDS, S.G. Fodder OATS: a world overview. Food and Agriculture Organization of the United Nations, 2004. Disponível em: <http:/ / www.fao.org/docrep/008/y5765e/ y5765e00.HTM>. Acesso em: 10 jan. 2009.
FINCH-SAVAGE, W.E.; LEUBNER-METZGER, G. Seed dormancy and the control of germination. New Phytologist, v.171, p.501-523, 2006.

FLOSS, E.L.; MELLO, N.; BESUTTI, A.; CAMARGO, A.S. Ensaio preliminar de aveias forrageiras, Passo Fundo, 2007. In: REUNIÃO DA COMISSÃO BRASILEIRA DE PESQUISA DE AVEIA, 28., 2008, Pelotas. Resultados experimentais... Pelotas: UFPel, 2008. p.453-457.

FOLEY, M.E.; FENNIMORE, S.A. Genetic basis for seed dormancy. Seed Science Research, v.8, p.173-182, 1998.

FONTANELI, R.S.; PIOVESAN, A.J. Efeito de cortes no rendimento de forragem e grãos de aveia, Passo Fundo, RS, 1988. Boletim de Pesquisa, n.10, p.62-69, 1990.

LEUBNER-METZGER, G. Functions and regulation of b-1,3glucanase during seed germination, dormancy release and after-ripening. Seed Science Research, v.13, p.17-34, 2003.

MOLITERNO, E. Variabilidade genética e a eficiência de seleção no caráter dormência de sementes em aveia preta (Avena strigosa Schreb.). 2008. 163f. Tese (Doutorado em Ciência e Tecnologia de Sementes) - Faculdade de Agronomia Eliseu Maciel, Universidade Federal de Pelotas, Pelotas.

MORENO A.J. Clima do Rio Grande do Sul. Porto Alegre: Secretaria da Agricultura, 1961. 41p.

OLIVEIRA, J. T. et al. Produção de forragem e grãos de cereais de duplo propósito em duas épocas de semeadura. In: REUNIÃO DA COMISSÃO BRASILEIRA DE PESQUISA DE AVEIA, 28., 2008, Pelotas. Resultados experimentais... Pelotas: UFPel, 2008. p.445-448.

RIZZARDI, M.A.; VARGAS, L. Papel trocado. Revista Cultivar, n.75, p.28-30, 2005.

SALERMO, A.; TCACENCO, F. Características técnicas do cultivo de forrageiras de estação fria no Vale do Itajaí e litoral de Santa Catarina. Florianópolis: EMPASC, 1985. 57p.

SANTOS, H.S.; REIS, E.M.; PÖTTKER, D. Culturas de inverno para plantio direto no sul do Brasil. Passo Fundo: EMBRAPA, CNPT, 1990. 24p. (Circular Técnica, 3)

SCHEFFER-BASSO, S.M.; FLOSS, E.L.; CECHETTI, D.; BARÉA, K.; BORTOLINI, F. Potencial de genótipos de aveia para duplo propósito. Revista Brasileira de Agrociência, v.7, p. 22-28, 2001.

SCHUCH, L.O.B.; NEDEL, J.L.; ASSIS, F.N.; MAIA, M.S. Vigor de sementes e análise de crescimento de aveia preta. Scientia Agricola, v.57, p.305-312, 2000. 